An-Nisbah: Jurnal Ekonomi Syariah

Volume 04, Nomor 02, April 2018

\title{
ANALISIS DAMPAK BRAND LOYALTY, BRAND AW ARENESS, PERCEIVED QUALITY DAN BRAND ASSOCLATION TERHADAP CUSTOMER VALUE PADA MAHASISWA FAKULTAS EKONOMI DAN BISNIS ISLAM IAIN TULUNGAGUNG
}

\author{
Rokhmat Subagiyo, M. Aqim Adlan \\ Dosen Ekonomi Syariah IAIN Tulungagung \\ mat97.eca@gmail.com
}

Abstract: The beginning of this research comes from the variable of brand loyalty, brand awareness, quality impression and brand association is expected to increase customer value. This is because the view of universities is a very broad discussion in order to be a contribution for students to feel satisfied with the services provided. The purpose of this study is to examine: the impact of Brand Loyalty, Brand Awareness, Quality Perceptions, and Brand Associations on Customer Value to students of the Faculty of Economics and Islamic Business IAIN Tulungagung. The research method used in this research is quantitative type elesplanotry research, with the type of causality relationship on the variables through bypothesis testing. The sample selection technique is done by using non probabality sampling method. Samples taken by students majoring in Sharia Economics, Islamic Banking, Syariah Accounting and Zakat Management and Endowments amounted to 359 respondents based on Slovin calculations. The analysis technique used is multiple linear regression analysis with SPSS program version 21. The result shows that brand loyalty, brand awareness, quality perception, brand association 
either partially or simultaneously bave a significant impact on customer value.

Keywords: Brand Loyalty, Brand Awareness, Quality Perceptions, Brand Associations, Customer Value.

Abstrak: Awal mula penelitian ini berasal dari variabel kesetiaan merek, kesadaran merek, kesan berkualitas dan asosiasi merek. diharapkan mampu meningkatkan nilai pelanggan. Hal ini karena pandangan tentang perguruan tinggi merupakan pembahasan yang sangat luas agar bisa menjadi sumbangsib bagi mahasiswa agar merasa puas terbadap pelayanan yang diberikan. Tujuan penelitian ini adalah untuk mengkaji: dampak Kesetiaan Merek, Kesadaran Merek, Persepsi Kualitas, dan Asosiasi Merek terhadap Nilai Pelanggan pada mahasiswa Fakultas Ekonomi dan Bisnis Islam IAIN Tulungagung. Metode penelitian yang digunakan dalam penelitian adalab kuantitatif berjenis eksplanotry research, dengan tipe bubungan kausalitas pada variabel-variabel melalui pengujian hipotesis. Teknik pemiliban sampel dilakukan dengan menggunakan metode sampel non probabalitas. Sampel yang diambil mahasiswa jurusan Ekonomi Syariah, Perbankan Syariah, Akuntansi Syariah dan Manajemen Zakat dan Wakaf berjumlah 359 responden berdasar perbitungan Slovin. Teknik analisis yang digunakan adalah analisis regresi linier berganda dengan program SPSS versi 21. Hasil menunjukkan bahwa kesetiaan merek, kesadaran merek, persepsi kualitas, asosiasi merek baik secara parsial maupun simultan mempunyai dampak yang signifikan terhadap nilai pelanggan.

Kata kunci: Kesetiaan Merek, Kesadaran Merek, Persepsi Kualitas, Asosiasi Merek, Nilai Pelanggan.

\section{PENDAHULUAN}

Era sekarang persaingan antar bisnis semakin tinggi, diikuti dengan bertambahnya jumlah pemain bisnis dalam menawarkan produk yang sama. Kekuatan pasar tidak terletak hanya pada gencarnya pemasaran, namun berfokus pada penilaian konsumen bahwa perusahaan tersebut telah memiliki reputasi yang baik atau 
Siti Kalimah, Nur Fadilah: Marketing Syariah.... [202]

perusahaan itu dianggap bermerek. Usaha yang telah dilakukan oleh perusahaan sangat menentukan berhasil atau tidak dalam membangun merek ke alam pikiran konsumen. Merek berguna sebagai identitas dan simbol pembeda baik logo, cap dan kemasan yang bertujuan untuk mengidentifikasikan barang atau jasa dari seorang penjual atau sebuah kelompok penjual tertentu.

Aset yang tidak berwujud dan dinilai amat berharga adalah ekuitas, yang diwakili oleh merek. Menurut pendapat yang dikutip dari Kotler dan Amstrong, "High Brand equity provides a company with many competitive advantage ${ }^{1 "}$. Maksudnya sebuah perusahaan dengan brand equity yang tinggi menyediakan banyak keuntungan kompetitif yang diperoleh, karena dengan mempunyai brand equity yang lebih kuat, diharapkan akan dengan mudah untuk menarik konsumen. Jadi dengan brand yang kuat akan mendorong pelanggan merasa 'nyaman' untuk melakukan pembelian ulang atau memberikan rekomendasi kepada orang lain.

Pendapat yang disampaikan oleh Kotler, merek adalah janji penjual untuk konsisten memberikan feature, manfaat dan jasa tertentu pada pembeli ${ }^{2}$. Dari sisi pelanggan atau pembeli, jumlah penawaran yang tertinggi sudah bisa diperkirakan. Pelanggan pasti menginginkan hasil yang maksimal, karena budget (anggaran) yang dipunyai terbatas. Dengan cara berusaha mencari informasi terkait produk (barang atau

1 Phillip Kotler anda Gary Amstrong. Principles of Marketing. International Edition. $7^{\text {th }}$ Edition. Upper Saddle River. (New Jersey: Prentice Hall International,2002), hal.284.

2 Phillip Kotle., Manajemen Pemasaran. Pemasaran, Analisis, Perencanana, Implementasi, dan Kontrol. Edisi Kesepuluh, (Jakarta: PT. Prehallindo, 2002), hal.63. 
jasa) yang ditawarkan. Merek yang dianggap bernilai tinggi, yang akan dihargai oleh konsumen, yang dianggap merefleksikan karakter pemakai merek tersebut.

Jika sebuah perusahaan mampu memberikan nilai yang lebih tinggi dibandingkan daripada pesaingya, maka perusahaan tersebut dinilai berhasil. Hal ini sesuai dengan pendapat Naumann yang mengatakan, "The most important success factor to a firm is the ability to deliver better customer value than competitor". Artinya Faktor keberhasilan sebagian besar perusahaan adalah dengan memberikan nilai yang lebih pada pelanggannya dibandingkan dengan pesaingnya. Bisa disimpulkan untuk dalam membangun customer value, sebuah perusahaan harus lebih memperhatikan manfaat yang akan diperoleh oleh konsumen daripada pengorbananya. Antar lain meliputi usaha, waktu dan biaya yang telah dikeluarkan konsumen dalam mendapatkan produk tersebut.

Rasa optimis dari dalam konsumen bisa dipengaruhi oleh ekuitas merek, jika ekuitas merek semakin tinggi akan mempermudah konsumen dalam memperoleh sebuah produk. Dengan semakin besar manfaat yang di dapatkan daripada pengorbanan yang dikeluarkan seorang konsumen. Dengan demikian produk tersebut akan dinilai sebagai produk yang bernilai tinggi oleh konsumen dibandingkan produk lain dan akan memperkuat rasa percaya diri. Merek yang sudah memiliki nama, dianggap sebagai perwujudan pengganti dari kualitas produk secara objektif oleh konsumen. Dan berfungsi untuk mengurangi tingkat resiko khususnya produk-produk yang

3 Earl Nauman.Creating Customer V alue: The Path to Suistanable Competitive Advantage. (Cincinati Ohio: Thompson Executive Press, 1995), hal. 15. 
Siti Kalimah, Nur Fadilah: Marketing Syariah.... [204]

berhubungan dengan jasa pelayanan seperti jasa layanan kesehatan, keamanan, kecantikan, keuangan dan pendidikan. Dengan demikian bisa disimpulkan bahwa tingkat kepercayaan pada sebuah merek beserta dengan reputasi yang dianggap berkualitas, bisa mencegah dan mengurangi tingkat resiko yang ada pada konsumen.

Terdapat lima elemen utama yang menjadi faktor-faktor pembentuk brand equity yaitu: brand loyalty, name awareness, perceived quality, brand association and other proprietary brand assets ${ }^{4}$. Kelima faktor atau elemen ini berpengaruh dalam membentuk customer value, yang berdampak loyalitas pelanggan. Loyalitas pelanggan diidentikan dengan loyalitas merek. Dalam manajemen pemasaran, brand equity menjadi ide sentral, karena menjadi salah satu ukuran hubungan antara pelanggan dengan sebuah merek. Jika loyalitas merek meningkat berdampak pada berkurangnya kerentanan serangan dari pesaing, sebab konsumen cenderung membeli merek yang sudah dikenal, agar merasa aman dengan sesuatu yang dikenal.

Keberadaan merek yang memiliki pengaruh besar terhadap nilai yang diterima oleh pelanggan benar-benar disadari oleh pihak pengelola Fakultas Ekonomi dan Bisnis Islam (FEBI) Institut Agama Islam Negeri (IAIN) Tulungagung, yaitu dengan berupaya terus untuk meningkatkan kualitas pelayanan seperti penyediaan fasilitas fisik seperti pembangunan gedung megah dengan lantai berjumlah 6 (enam) dengan dilengkapi lift elevator untuk mempermudah mencapai kelas atau ruangan yang sesuai jadwal yang ada. Kualitas dosen

\footnotetext{
${ }^{4}$ David A. Aaker. Managing Brand Equity: Capitalizing on the V alue of Brand Name. (New York: The Free Press, 1998), hal. 23.
} 
ditingkatkan dengan memberi kemudahan untuk melanjutkan pendidikan yang lebih tinggi.

Agar bisa memenangkan persaingan pihak pengelola FEBI IAIN Tulungagung terus berupaya memperbaiki pelayanan pada pengguna jasanya yaitu para mahasiswa. Menguptodate kurikulum tiap akhir semester supaya tidak ketinggalan jaman, dengan selalu mengajak duduk bersama para citivitas akademika dan stake holder, seperti dosen, unsure pimpinan dan praktisi ekonomi syariah dalam forum workshop kurikulum dan silabus. Pada dasarnya proses belajar mengajar di FEBI IAIN Tulungagung memiliki kesamaan dengan perguruan tinggi yang menawarkan keilmuan yang sama. Yang membedakan antara Fakultas Ekonomi dan Bisnis Islam IAIN Tulungagung dengan para pesaingnya adalah variasi kelimuan agama Islamnya, di samping transfer kelimuan ekonomi murni, seperti hafalan ayat-ayat maupun hadits-hadits ekonomi.

Pada awalnya, segmen pasar FEBI hanya terbatas pada kalangan pada 3 (tiga) jurusan saja, namun saat ini berupaya memperluas segmen pasarnya dengan menambah 2 (dua), yakni Manajemen Keuangan Islam (MKI) dan Manajemen Bisnis Islam (MBI) dan 1 (satu) pindahan dari fakultas syariah dan ilmu hukum yaitu Manajemen Zakat dan Wakaf (Mazawa). Sehingga saat ini sudah ada 6 (enam) jurusan yaitu: Perbankan Syariah (PS), Ekonomi Syariah (ES), Akuntansi Syariah (AkSy), Manajemen Zakat dan Wakaf (Mazawa), Manajemen Keuangan Islam (MKI) dan Manajemen Bisnis Islam (MBI). Sedangkan pesaingnya secara umum hanya mempunyai 1 atau 
2 pilihan jurusan, sehingga calon mahasiswa memiliki banyak pilihan jurusan sesuai dengan keinginan mereka.

\section{KERANGKA TEORI}

\section{Brand Loyalty (Kesetiaan Merek)}

Menurut Solomon et.al, definisi brand loyalty (Loyalitas merek), adalah "brand loyalty is a form of repeat purchasing behaviour reflecting a conscious decision to continue buying the same brand ${ }^{5}$. Maksudnya, brand loyalty merupakan bentuk perilaku pembelian ulang yang mencerminkan sebuah kegiatan dengan sadar dilakukan untuk melanjutkan pembelian untuk merek yang sama. Assael mendefinisikan brand loyalty adalah "repeat buying because of commitment to a brand". Artinya, brand loyalty merupakan tindakan pembelian ulang dikarenakan komitmen atas sebuah merek. Jadi brand loyalty berhubungan dengan satu ukuran keterkaitan seorang pelanggan pada sebuah merek brand loyalty atau loyalitas merek diukur dari tingkat kesetiaan konsumen terhadap merek. Apabila loyalitas merek meningkat, maka kerentanan kelompok pelanggan dari serangan kompetitor dapat dikurangi. Hal ini menunjukkan suatu indikator dari ekuitas merek yang berkaitan dengan perolehan laba di masa yang akan datang karena loyalitas merek dapat diartikan sebagai peluang penjualan bagi perusahaan di masa depan.

\footnotetext{
${ }^{5}$ Michael Solomon, Gary Bamossy, Søren Askegaard dan Margaret K. Hogg. Consumer Behaviour A European Perspective. $3^{\text {nd }}$ Edition, (New York: Prentice Hall, 2006), hal.289.

${ }^{6}$ Henry Assael, Consumer Behavior and Marketing Strategy. (Cincinnati: South Western Collage Publishing 2002),hal.103
} 


\section{Brand Awareness (Kesadaran Merek)}

Menurut Durianto, dkk brand awareness adalah kesanggupan seorang calon pembeli untuk mengenali, mengingat kembali suatu merek sebagai bagian dari suatu kategori produk tertentu ${ }^{7}$. Jadi kesadaran merek adalah kemampuan konsumen untuk mengenal atau mengingat sebuah merek pada produk yang berbeda bergantung pada tingkat komunikasi merek atau pada persepsi konsumen. Tingkatan brand awareness yang dikemukakan oleh Handayani, $\mathrm{dkk}^{8}$ :

1. Unware of brand (tidak menyadari merek) adalah tingkat yang paling rendah dalam piramida kesadaran merek, di mana konsumen tidak menyadari akan adanya suatu merek.

2. Brand recognition (pengenalan merek) adalah tingkat minimal dari kesadaran merek. Hal ini penting pada saat seorang pembeli memilih suatu merek dalam melakukan pembelian.

3. Brand recall (peringatan kembali terhadap merek) adalah pengingatan kembali terhadap merek didasarkan pada permintaan seseorang untuk menyebutkan merek tertentu dalam suatu kelas produk. Hal ini diistilahkan dengan pengingatan kembali tanpa bantuan, karena berbeda dari tugas pengenalan, responden tidak perlu dibantu untuk memunculkan merek tersebut.

4. Top of Mind (puncak pikiran) adalah apabila seseorang ditanya secara langsung tanpa diberi bantuan pengingatan dan ia dapat menyebutkan satu nama merek, maka merek yang paling banyak

\footnotetext{
${ }^{7}$ Durinto, Darmanto, Sugiarto dan Toni Siitnjak. Strategi Menaklukan Pasar Melalui Riset Ekuitas dan Perilaku (Jakarta: PT. SUN, 2004), hal.30.

${ }^{8}$ Desy Handayani dkk. The Official MIM Academy Coursebook Brand Operation. (Jakarta: Esensi Grup, 2010), hal.65.
} 
Siti Kalimah, Nur Fadilah: Marketing Syariah.... [208]

disebutkan pertama sekali dapat dikatakan sebagai puncak pikiran. Merek tersebut menjadi merek utama dari berbagai merek yang ada di dalam benak konsumen.

\section{Perceived Quality (persepsi kualitas)}

Aaker dalam Handayani, dkk, mendefinisikan perceived quality sebagai persepsi konsumen terhadap kualitas atau keunggulan suatu produk atau jasa sehubungan dengan tujuan yang diinginkannya, dibandingkan dengan alternatif-alternatif lain. Sedangkan Simamora menyatakan bahwa persepsi kualitas adalah persepsi konsumen terhadap kualitas atau keunggulan suatu produk atau jasa layanan ditinjau dari fungsinya secara relatif dengan produk-produk lain ${ }^{10}$. Jadi persepsi kualitas adalah persepsi yang dimiliki oleh pelanggan secara keseluruhan atas kualitas atau keunggulan sebuah produk atau layanan yang berhubungan dengan harapan yang ada.

\section{Brand Association (Asosiasi Merek)}

Aaker dalam Handayani, dkk, mendefinisikan brand association sebagai segala sesuatu yang terhubung di memori konsumen terhadap suatu merek ${ }^{11}$. Sedangkan menurut Simamora, asosiasi merek adalah segala hal yang berkaitan tentang merek dalam ingatan ${ }^{12}$. Jadi asosiasi bukan sekedar eksis, tetapi mempunyai suatu sebuah kekuatan. Berhubungan dengan banyak pengalaman atau penampakan untuk

\footnotetext{
${ }^{9}$ Ibid, hal.84.

${ }^{10}$ Bilson Simamora. Memenangkan Pasar dengan Pasar Efektif dan Profiatbel. Edisi Pertama, (Jakarta: Gramedia Pustaka Utama), 1998), hal.78

${ }^{11}$ Desy Handayani dkk, The Official................., hal.84.

12 Bilson Simamora, Memenangkan Pasar.......,hal.63.
} 
mengkomunikasikannya. Berbagai asosiasi yang diingat konsumen dapat dirangkai sehingga membentuk citra tentang merek atau brand image di dalam benak konsumen.

\section{Customer Value (Nilai Pelanggan)}

Definisi nilai pelanggan atau customer value menurut Philip Kotler dan Kevin Lane Keller "is the difference between the prospective customer's evaluation of all the benefits and all the costs of an offering and the

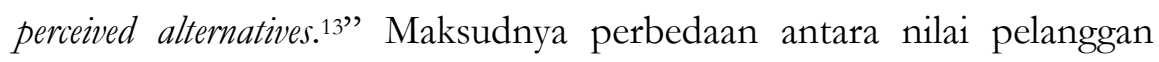
total (total customer value) dan biaya pelanggan total (total customer cost). Selanjutnya menurut Kotler dan Amstrong, yang dikutip oleh Amin Widjaja Tunggal adalah selisih antara total customer value (jumlah nilai bagi pelanggan) dan total customer cost (biaya total pelanggan) ${ }^{14}$. Nilai pelanggan total (total customer value) adalah sekumpulan manfaat yang diharapkan oleh pelanggan dari produk atau jasa tersebut. Biaya pelanggan total (total customer value) adalah sekumpulan biaya yang diharapkan oleh konsumen yang dikeluarkan oleh konsumen untuk mengevaluasi mendapatkan, menggunakan dan membuang produk dan jasa. Menurut Buchory Customer V alue atau nilai pelanggan adalah selisih antara evaluasi calon pelanggan atas semua manfaat serta semua biaya tawaran tertentu dan alternatif-alternatif yang dipikirkan. Nilai pelanggan terdiri dari dua dimensi, yaitu: Nilai pelanggan total adalah nilai moneter yang dipikirkan atas sekumpulan manfaat ekonomis,

\footnotetext{
13Philiip Kotler dan Kevin Lane Keller. Marketing Management (14ed). (New Jersey: Pearson Education, 2012), hal.124.

${ }^{14}$ Amin Widjaja Tunggal.

Dasar Dasar Customer Relationship Management. ( Jakarta: Harvarindo, 2008), hal.18.
} 
Siti Kalimah, Nur Fadilah: Marketing Syariah.... [210]

fungsional dan psikologis yang diharapkan pelanggan atas tawaran pasar tertentu yang terdiri dari nilai produk, nilai pelayanan, nilai karyawan, dan nilai citra. Nilai biaya total adalah sekumpulan biaya yang dikeluarkan pelanggan untuk mengevaluasi, mendapatkan, menggunakan dan membuat tawaran pasar tertentu yang terdiri dari: biaya moneter, biaya waktu, biaya energi, dan biaya mental/psikis. Dari pengertian tersebut customer value (nilai pelanggan) yang dikemukakan oleh pakar pemasaran diatas, maka penulis merangkum variabel-variabel nilai pelanggan diatas menjadi tiga variabel penelitian, yaitu: nilai produk, nilai pelayanan, dan nilai harga.

\section{METODOLOGI PENELITIAN}

Hipotesis dalam penelitian ini terdiri atas lima (5) antara lain: (1) brand loyalty berdampak terhadap customer value pada mahasiswa Fakultas Ekonomi dan Bisnis Islam IAIN Tulungagung; (2) brand awareness berdampak terhadap customer value pada mahasiswa Fakultas Ekonomi dan Bisnis Islam IAIN Tulungagung; (3) perceived quality berdampak terhadap customer value pada mahasiswa Fakultas Ekonomi dan Bisnis Islam IAIN Tulungagung; (4) brand association berdampak terhadap customer value pada mahasiswa Fakultas Ekonomi dan Bisnis Islam IAIN Tulungagung dan (5) brand loyalty, brand awareness, perceived quality dan brand association berdampak secara simultan terhadap customer value pada mahasiswa Fakultas Ekonomi dan Bisnis Islam IAIN Tulungagung. Teknik pengambilan sampel menggunakan rumus Slovin. Teknik pemilihan sampel dilakukan dengan menggunakan metode sampel non probabalitas. Artinya, teknik pengambilan sampel 
yang ditentukan peneliti sesuai pertimbangan-pertimbang tertentu, dengan tidak memberikan peluang yang sama terhadap anggota populasi untuk menjadi sampel. Melalui perhitungan sampel menggunakan rumus Slovin $\left(\mathbf{n}=\frac{N}{\mathbf{1}+N \cdot \boldsymbol{e}^{\mathbf{2}}}\right)$ dengan toleransi kesalahan 5\% diperoleh jumlah sampel sebanyak 359 responden.

\section{HASIL PENELITIAN}

Hasil penelitian menunjukkan bahwa ada dampak Brand loyalty terhadap customer value pada mahasiswa Fakultas Ekonomi dan Bisnis Islam IAIN Tulungagung, karena nilai signifikansi sebesar 0,003; Hal ini berarti apabila Brand loyalty ini ditingkatkan, maka customer value pada mahasiswa Fakultas Ekonomi dan Bisnis Islam IAIN Tulungagung. Brand awareness berdampak terhadap customer value pada mahasiswa Fakultas Ekonomi dan Bisnis Islam IAIN Tulungagung, karena nilai signifikansi sebesar 0,000. Hasil tersebut, yang berarti apabila faktor-faktor pada Brand awareness meningkat, maka akan meningkatkan customer value pada mahasiswa Fakultas Ekonomi dan Bisnis Islam FEBI IAIN Tulungagung. Perceived quality berdampak terhadap customer value pada mahasiswa Fakultas Ekonomi dan Bisnis Islam IAIN Tulungagung. Hasil ini mendukung hipotesis ketiga, karena Perceived quality menambah tingkat customer value pada mahasiswa FEBI IAIN Tulungagung secara langsung. Ada dampak Brand association terhadap customer value pada mahasiswa Fakultas Ekonomi dan Bisnis Islam IAIN Tulungagung, dengan nilai signifikansi 0,000 dengan besar pengaruh sebesar 0,330. Berarti semakin faktor-faktor Brand association ditingkatkan maka customer value 
Siti Kalimah, Nur Fadilah: Marketing Syariah.... [212] pada mahasiswa Fakultas Ekonomi dan Bisnis Islam IAIN Tulungagung akan meningkat pula. Brand loyalty, brand awareness, perceived quality dan brand association berdampak secara simultan terhadap customer value pada mahasiswa Fakultas Ekonomi dan Bisnis Islam IAIN Tulungagung. Dengan nilai signifikasi sebesar 0,000; besarnya pengaruh Brand loyalty, brand awareness, perceived quality dan brand association terhadap customer value sebesar 0,000. yang berarti semakin Brand loyalty, brand awareness, perceived quality dan brand association ditingkatkan maka customer value FEBI IAIN Tulungagung akan meningkat pula.

\section{PEMBAHASAN}

Dampak Brand Loyalty $\left(\mathrm{X}_{1}\right)$ Terhadap Customer Value Pada Mahasiswa Fakultas Ekonomi Dan Bisnis Islam IAIN

\section{Tulungagung}

Hasil menunjukkan dampak positif variabel kesetiaan merek terhadap nilai pelanggan. Hal ini disebabkan oleh Customer Value dipengaruhi oleh faktor-faktor yang mempengaruhi Brand Equity yaitu Brand Loyalty yang merupakan faktor yang signifikan dalam Customer $V$ alue. Pada variabel Brand Loyalty, total mean yang diperoleh adalah 4,25. Hal ini menunjukkan tingkat kesetiaan responden terhadap Fakultas Ekonomi dan Bisnis Islam (FEBI) IAIN Tulungagung masih tergolong baik. Hal ini dikarenakan secara mayoritas mahasiswa yang kuliah di FEBI akan tetap mengikuti perkuliahan sampai mereka lulus. Besarnya dampak Brand Loyalty terhadap customer value ini sesuai dengan pendapat Aaker, yaitu diagnosa terpenting untuk setiap 
tingkatan loyalitas merek adalah pengukuran terhadap kepuasan atau ketidakpuasan ${ }^{15}$. Hasil ini sesuai dengan hasil penelitian dari Herma Yunitasari dan Ahyar Yuniawan yang menyatakan Kesadaran merek (brand awareness), persepsi kualitas (perceived quality), dan loyalitas merek (brand loyalty) secar parsial dan simultan berpengaruh signifikan dan positif terhadap nilai pelanggan ${ }^{16}$.

\section{Dampak Brand Awareness $\left(\mathbf{X}_{2}\right)$ Terhadap Customer Value Pada}

\section{Mahasiswa Fakultas Ekonomi Dan Bisnis Islam IAIN}

\section{Tulungagung}

Hasil menunjukkan dampak positif variabel kesetiaan merek terhadap nilai pelanggan. Hasil analisis data secara statistik membuktikan bahwa terdapat dampak signifikan antara Brand Awareness $\left(\mathrm{X}_{2}\right)$ Terhadap Customer Value Pada Mahasiswa Fakultas Ekonomi Dan Bisnis Islam IAIN Tulungagung yang ditunjukkan dengan nilai standardized direct effect sebesar dapat diketahui bahwa faktor Brand Awareness $\left(\mathrm{X}_{2}\right)$ memiliki nilai koefisien regresi 0,439; mempunyai nilai signifikansi t sebesar 0,000; sehingga berdampak secara positif dan signifikan terhadap Customer V alue Mahasiswa. Hasil penelitian sesuai dengan jawaban responden pada tabel 4.2, total ratarata yang diperoleh sebesar 3,96 atau dibulatkan menjadi 4. Hal ini menunjukkan bahwa tingkat kesadaran konsumen sudah cukup baik.

\footnotetext{
${ }^{15}$ David A. Aaker. Manajemen Ekuitas Merek Memanfaatkan Nilai Dari Suatu Merek. terjemahan. (Jakarta: Penerbit Mitra Utama, 1997), hal.64.

${ }^{16}$ Herma Yunitasari, Ahyar Yuniawan. Analisis Pengaruh Kesadaran Merek, Persepsi Kualitas Dan Loyalitas Merek Terhadap Nilai Pelanggan Mobil Merek Toyota, Volume 3, Nomor 2, Juli, Tabun 2006, Halaman 15.// http:// ejournal.undip.ac.id/index.php/smo, yang diakses pada 4 April 2017, pada $21.00 \mathrm{WIB}$
} 
Responden hanya mengenal logo FEBI, akan tetapi tidak mengetahui jenis jurusan yang ada di FEBI IAIN Tulungagung akibat jarang mengakses internet ataupun leaflet/brosur/booklet yang minim sekali. Hal ini tidak sesuai dengan pendapat Kotler, yang mengatakan Citra yang kuat terdiri satu lambang atau lebih yang memicu pengenalan perusahaan atau merek $^{17}$.

Hasil Penelitian ini sesuai dengan hasil penelitian yang dilakukan Herma Yunitasari dan Ahyar Yuniawan (2006) yang menyatakan Kesadaran merek (brand awareness), persepsi kualitas (perceived quality), dan loyalitas merek (brand loyalty) secar parsial dan simultan berpengaruh signifikan dan positif terhadap nilai pelanggan ${ }^{18}$. Hasil ini pula didukung oleh teori tentang brand awareness adalah kesanggupan seorang calon pembeli untuk mengenali, mengingat kembali suatu merek sebagai bagian dari suatu kategori produk tertentu ${ }^{19}$.

\section{Dampak Perceived Quality $\left(\mathbf{X}_{3}\right)$ terhadap Customer Value Pada Mahasiswa Fakultas Ekonomi Dan Bisnis Islam IAIN Tulungagung}

Hasil perhitungan statistik telah membuktikan bahwa Perceived Quality yang dibentuk oleh keseluruhan pelayanan yang diberikan oleh

\footnotetext{
${ }^{17}$ Philip Kotler. Manajemen Pemasaran, Analisis, Perencanaan, Implementasi dan Kontrol. Jilid 1. Edisi Bahasa Indonesia. (Jakarta: PT. Prehallindo, 199.8), hal.260.

${ }^{18}$ Herma Yunitasari, Ahyar Yuniawan. Analisis Pengaruh Kesadaran Merek, Persepsi Kualitas Dan Loyalitas Merek Terhadap Nilai Pelanggan Mobil Merek Toyota. Volume 3, Nomor 2, Juli, Tabun 2006, Halaman 15.// bttp://ejournal.undip.ac.id/index.php/smo, yang diakses pada 4 April 2017, pada $21.00 \mathrm{WIB}$

${ }^{19}$ Durinto, Darmanto, Sugiarto dan Toni Sitinjak. Strategi Menaklukan Pasar Melalui Riset Ekuitas dan Perilaku.(Jakarta: PT. SUN, 2004), hal.30.
} 
FEBI, perbandingan kualitas pelayanan dengan kampus lain dan jaminan bagi alumni setelah lulus memiliki dampak yang positif dan signifikan terhadap Customer Value Pada Mahasiswa Fakultas Ekonomi Dan Bisnis Islam IAIN Tulungagung. Bauran pemasaran mempunyai nilai koefisien regresi 0,741 ; mempunyai nilai signifikansi t sebesar 0,000. Hal ini berarti apabila Perceived Quality meningkat sebesar 1 (satu) satuan maka customer value akan meningkat sebesar 0,741 satu satuan pula.

Hasil penelitian ini konsisten dengan pendapat dari Aaker dalam Handayani, dkk, mendefinisikan perceived quality sebagai persepsi konsumen terhadap kualitas atau keunggulan suatu produk atau jasa sehubungan dengan tujuan yang diinginkannya, dibandingkan dengan alternatif-alternatif lain ${ }^{20}$. Hasil ini didukung juga oleh Herma Yunitasari dan Ahyar Yuniawan (2006) ${ }^{21}$ yaitu yang menyatakan Kesadaran merek (brand awareness), persepsi kualitas (perceived quality), dan loyalitas merek (brand loyalty) secar parsial dan simultan berpengaruh signifikan dan positif terhadap nilai pelanggan.

Hal ini selaras dengan hasil jawaban responden seperti pada tabel 4.3 yang menunjukkan bahwa perceived quality dengan nilai ratarata (mean) 3,44 atau dibulatkan menjadi 3,5; yang berarti kurang baik menurut penilaian atau persepsi mahasiswa FEBI tentang kesan berkualitas atas pelayanan yang diberikan oleh pengelola FEBI. Mulai

\footnotetext{
${ }^{20}$ Desy Handayani dkk, The Official ...., hal.84.

${ }^{21}$ Herma Yunitasari dan Ahyar Yuniawan. Analisis Pengaruh Kesadaran Merek, Persepsi Kualitas Dan Loyalitas Merek Terhadap Nilai Pelanggan Mobil Merek Toyota, Volume 3, Nomor 2, Juli, Tabun 2006, Halaman 15.// http://ejournal.undip.ac.id/index.php/smo, yang diakses pada 4 April 2017, pada 21.00 WIB
} 
pelayanan secara keseluruhan, perbandingan pelayanan pihak FEBI dengan perguruan tinggi lain dan mahasiswa merasa masih belum memperoleh jaminan pada alumninya saat lulus.

\section{Dampak Brand Association Terhadap Customer Value Pada Mahasiswa Fakultas Ekonomi Dan Bisnis Islam IAIN Tulungagung}

Tabel 4.15 menunjukkan bahwa Brand Association berdampak signifikan dan positif Terhadap Customer Value Pada Mahasiswa. Hal ini sesuai dengan hipotesis yakni Brand Association Terhadap Customer Value Pada Mahasiswa Fakultas Ekonomi Dan Bisnis Islam IAIN Tulungagung. Brand Association mempunyai nilai koefisien regresi 0,330; mempunyai nilai signifikansi t sebesar 0,000, berarti apabila Brand Association meningkat sebesar 0,330 maka tingkat Customer Value akan meningkat sebesar 0,330.

Hasil penelitian ini konsisten dengan jawaban responden (tabel 4.4) dengan rata-rata mean 3,82 dibulatkan menjadi 4, yang berarti responden menganggap materi selama perkuliahan bermanfaat dalam dunia kerja, metode pengajaran yang tepat dan durasi waktu perkuliahan yang fleksibel sesuai dengan yang dibutuhkan dan diinginkan mahasiswa.

Hal ini sesuai dengan pendapat yang disampaikan oleh Simamora, asosiasi merek adalah segala hal yang berkaitan tentang merek dalam ingatan ${ }^{22}$. Jadi asosiasi bukan sekedar eksis, tetapi mempunyai suatu sebuah kekuatan. Berhubungan dengan banyak

\footnotetext{
22 Bilson Simamora, Memenangkan Pasar.......,hal.63.
} 
pengalaman atau penampakan untuk mengkomunikasikannya. Berbagai asosiasi yang diingat konsumen dapat dirangkai sehingga membentuk citra tentang merek atau brand image di dalam benak konsumen.

Dampak Brand Loyalty, Brand Awareness, Perceived Quality Dan Brand Association Terhadap Customer Value Pada Mahasiswa Fakultas Ekonomi Dan Bisnis Islam IAIN Tulungagung

Dalam penelitian ini, Brand Loyalty, Brand Awareness, Perceived Quality Dan Brand Association berdampak secara simultan Terhadap Customer Value. Karena mempunyai nilai signifikansi F sebesar 0,000, berarti apabila Brand Association. Hasil penelitian ini sama dengan penelitian yang dilakukan oleh Gandung Sujatmiko (2004) ${ }^{23}$, yaitu Brand Loyalty, Brand Awareness, Perceived Quality Dan Brand Association berpengaruh signifikan terhadap Customer Value pada konsumen Berri Juice di Surabaya baik secara simultan maupun parsial.

Hasil penelitian ini selaras dengan jawaban responden terkait Customer Value (lihat tabel 4.5) yang memiliki nilai rata-rata 3,74 dibulatkan menjadi 4, yang bermakna mayoritas responden beranggapan secara umum layanan dan kinerja baik staf administrasi dan akademik memuaskan. Hal ini juga sesuai dengan hasil penelitian yang dilakukan oleh Aaker yang menyebutkan bahwa brand equity dengan elemen-elemennya (brand loyalty, brand awareness, perceived quality dan brand association) mempunyai pengaruh yang signifikan terhadap customer value.

${ }^{23}$ Gandung Sujatmiko. Pengaruh ...., hal.59-60. 
Siti Kalimah, Nur Fadilah: Marketing Syariah.... [218]

\section{KESIMPULAN}

Penelitian ini menghasilkan kesimpulan sebagai berikut:

1. Ada dampak Brand loyalty terhadap customer value pada mahasiswa Fakultas Ekonomi dan Bisnis Islam IAIN Tulungagung., karena nilai signifikansi sebesar 0,003. Dengan besar pengaruh sebesar 0,143 . Hasil ini mendukung hipotesis pertama. Hal ini berarti apabila Brand loyalty ini ditingkatkan, maka customer value pada mahasiswa Fakultas Ekonomi dan Bisnis Islam IAIN Tulungagung.

2. Brand awareness berdampak terhadap customer value pada mahasiswa Fakultas Ekonomi dan Bisnis Islam IAIN Tulungagung, karena nilai signifikansi sebesar 0,000 . Besarnya pengaruh bauran pemasaran kepada kepuasan mahasiswa adalah 0,439. Hasil tersebut menerima hipotesis kedua, yang berarti apabila faktorfaktor pada Brand awareness meningkat, maka akan meningkatkan customer value pada mahasiswa Fakultas Ekonomi dan Bisnis Islam FEBI IAIN Tulungagung.

3. Perceived quality berdampak terhadap customer value pada mahasiswa Fakultas Ekonomi dan Bisnis Islam IAIN Tulungagung. Hasil ini mendukung hipotesis ketiga, karena Perceived quality menambah tingkat customer value pada mahasiswa FEBI IAIN Tulungagung secara langsung.

4. Ada dampak Brand association terhadap customer value pada mahasiswa Fakultas Ekonomi dan Bisnis Islam IAIN Tulungagung, dengan nilai signifikansi 0,000 dengan besar pengaruh sebesar 0,330. Hal ini sesuai dengan hipotesis keempat, yang berarti 
Siti Kalimah, Nur Fadilah: Marketing Syariah....[219] semakin faktor-faktor Brand association ditingkatkan maka customer value pada mahasiswa Fakultas Ekonomi dan Bisnis Islam IAIN Tulungagung akan meningkat pula

5. Brand loyalty, brand awareness, perceived quality dan brand association berdampak secara simultan terhadap customer value pada mahasiswa Fakultas Ekonomi dan Bisnis Islam IAIN Tulungagung. Dengan nilai signifikasi sebesar 0,000 yang berarti mendukung hipotesis kelima yang diajukan dalam penelitian ini. Besarnya pengaruh Brand loyalty, brand awareness, perceived quality dan brand association terhadap customer value sebesar 0,000. yang berarti semakin Brand loyalty, brand awareness, perceived quality dan brand association ditingkatkan maka customer value FEBI IAIN Tulungagung akan meningkat pula. 
Siti Kalimah, Nur Fadilah: Marketing Syariah.... [220]

\section{DAFTAR PUSTAKA}

Aaker, David A. Managing Brand Equity: Capitalizing on the Value of Brand Name, New York: The Free Press, 1998.

Akbar, Haryadi. Analisis Pengaruh Brand Equity Teh Botol Sosro Terhadap Loyalitas Pembelian Pada Mahasiswa Fakultas Ekonomi Dan Bisnis Universitas Hasanuddin, Skripsi-FEBUniversitas Hasanudin, 2012.

Assael, Henry. Consumer Behavior and Marketing Strategy. (Cincinnati: South Western Collage Publishing, 2002.

Baldauf, Artur dkk. Performance Consequences of Brand Equity Managament : Evidence From Organizatoin In The Value Chain,Journal of Product End Brand Management. 2003,Vol.12 No.14.

Boyd, Walker Orville Jr Harper W, Jr Mullins, Larrache, Jean Claude. Manajemen Pemasaran. Jakarta: Erlangga, Edisi Kedua, 2001.

Cooper, Donald R \& C. William Emory. Metode Penelitian Bisnis 2. Jakarta: Erlangga, 1998.

Durinto, Darmanto, Sugiarto dan Toni Sitinjak. Strategi Menaklukan Pasar Melalui Riset Ekuitas dan Perilak., Jakarta: PT. SUN, 2004 Febi.iain-tulungagung.ac.id, yang diakses pada 2 Oktober 2017 pukul 22.00WIB. 
Ferrinadewi, Erna. Merek \& Psikologi Konsumen: Implikasi pada Strategi Pemasaran. Edisi Pertama, Cetakan Pertama, Yogyakarta: Graha Ilmu, 2008.

Ghozali,Imam. Aplikasi Analisis Multivariate dengan Program SPSS. Semarang: BP UNDIP, 2007.

Gujarati, Damodar N. Dasar-dasar ekonometrika . buku 2 edisi 5.Jakata: Salemba. 2012.

Handayani, Desy dkk. The Official MIM Academy Coursebook Brand Operation. Jakarta: Esensi Grup, 2010.

Istijanto. Aplikasi Praktis Riset Pemasaran - Cara Praktis Meneliti Konsumen dan Pesaing (Edisi Revisi). Jakarta: Gramedia Pustaka Utama,2002.

Jiwandono, Dewangga Teguh. Pengaruh Customer Value Terhadap Loyalitas Pelanggan, https://openlibrary.telkomuniversity.ac.id/.../pengaruhcustomer-value-terhadap-loyali... yang diakses pada 11 April 2017, pada 24.00 WIB

Juariah dan Hamka, Pengaruh Brand Equity Terhadap Loyalitas Mahasiswa Terhadap Laptop Di Universitas Muhammadiyah Palembang, jurnal.umpalembang.ac.id/index.php/ilmu_manajemen/article/view/423/386 yang diakses pada 12 April 2017, pada 20.00 WIB

Kardes,Frank R. Maria L. Cronley,Thomas W. Cline. Consumer Behavior. Mason: South-Western, Cengage Learning, 2011. Kertajaya, Hermawan. Marketing Plus 2000: Siasat Memenangkan Persaingan Global. Jakarta: PT. Gramedia Utama,1999. 
Kotler, Philiip dan Kevin Lane Keller, Marketing Management (14ed). (New Jersey: Pearson Education, 2012.

Kotler, Phillip anda Gary Amstrong, Principles of Marketing. International Edition. $7^{\text {th }}$ Edition. Upper Saddle River. (New Jersey: Prentice Hall Internationa), 2002

Kotler, Phillip. Manajemen Pemasaran, Analisis, Perencanana, Implementasi, dan Kontrol. Edisi Kesepuluh, Terjemahan. Jakarta : PT. Prehallindo, 2002.

Kuncoro,Mudrajad. Metode Riset Untuk Bisnis dan Ekonomi. Jakarta: Penerbit Erlangga, 2003.

Logiawan, Yenny dan Hartono Subagio. Analisa Customer Value Terhadap Customer Loyalty Dengan Customer Satisfaction Sebagai Variabel Intervening Pada Restoran Bandar Djakarta Surabaya. Jurnal Manajemen Pemasaran Petra Vol. 2, No. 1, (2014) $1-11$

Nauman, Earl. Creating Customer Value: The Path to Suistanable Competitive Advantage. Cincinati Ohio: Thompson Executive Press, 1995.

Nisa, Anne dan Jannatun. Pengaruh Ekuitas Merek Dan Nilai Pelanggan Terhadap Loyalitas Pelanggan (Survei Pada Pelanggan Sari Ater Hotel \& Resort Di Subang). http://elib.unikom.ac.id/files/disk1/650/jbptunikompp-gdlannejannat-32473-11-unikom a-l.pdf. yang diakses pada 12 april 2017, pada 20.30 WIB.

Prasetyo, Bambang dan Lina Miftahul Jannah. Metode Penelitian Kuantitatif. Jakarta: PT. Raja Grafindo Persada, 2005. 
Santoso, Singgih. SPSS Versi 10 Mengolah Data Statistik Secara Profesional. Jakarta: PT. Media Komputindo, 2002.

Simamora, Bilson. Memenangkan Pasar dengan Pasar Efektif dan Profitabel.

Edisi Pertama, Jakarta: Gramedia Pustaka Utama,1998.

Singarimbun, Masri dan Sofian Efendi. Metode Penelitian Survai. Jakarta: LP3ES, 1989.

Solomon,Michael Gary Bamossy, Søren Askegaard dan Margaret K. Hogg. Consumer Behaviour A European Perspective. $3^{\text {nd }}$ Edition,New York: Prentice Hall, 2006

Stanton, William Michael J. Etzel dan Bruce J Walker. Fundamental of Marketing. International Edition. New Jersy: McGraw-Hill Inc, 1991.

Subagiyo,Rokhmat. Metode Penelitian Ekonomi Islam: Konsep dan Penerapan. Jakarta: Alim's Publishing, 2017.

Sugiyono. Metode Penelitian Kuantitatif, Kualitatif dan Kombinasi (Mixed). Bandung: Alfabeta, 2015.

Sujatmiko, Gandung. Pengaruh Elemen-Elemen Brand Equity Terhadap Customer Value Pada Konsumen Berri Juice Di Surabaya, (Skripsi-Fakultas Ekonomi Universitas Airalngga), 2014.

Tunggal, Amin Widjaja, Dasar Dasar Customer Relationship Management. Jakarta: Harvarindo, 2008.

Tjiptono, Fandy, Brand Management and Strategy, Yogyakarta: Andi, 2005. 
Siti Kalimah, Nur Fadilah: Marketing Syariah.... [224]

Ujang, Sumarwan. Perilaku Konsumen: Teori dan Penerapannya Dalam Pemasaran. Cetakan Pertama, Jakarta: Penerbit Ghalia Indonesia, 2003.

Umar, Husein. Riset Pemasaran \& Perilaku Konsumen. Jakarta: PT. Gramedia Pusaka Utama, 2002.

Wijaya, Tony. Analisis Data Penelitian Menggunakan SPSS. Yogyakarta: Universitas Atma Jaya, 2009.

Yunitasari, Herma dan Ahyar Yuniawan. Analisis Pengaruh Kesadaran Merek, Persepsi Kualitas Dan Loyalitas Merek Terhadap Nilai Pelanggan Mobil Merek Toyota.Volume 3, Nomor 2, Juli, Tahun 2006, Halaman 15.// http://ejournal.undip.ac.id/index.php/smo, yang diakses pada 4 April 2017, pada 21.00 WIB. 